\title{
Bird Strike Risk Control in Meizhou Airport Based on Cascading Failure Model in Coupled Map Lattices
}

\author{
Liang Qiao ${ }^{1}{ }^{*}$ \\ ${ }^{1}$ School of Airport Management, Civil Aviation College of Guangzhou, Guangdong, China
}

\begin{abstract}
The fundamental way to reduce the risk of bird strike is to manage the ecological environment of the airport and its surrounding areas and affect the ecological chain of birds. Based on a comprehensive survey of animal and plant populations in Meizhou airport, an airport ecological chain network is established, and a improved cascading failure model in coupled map lattices is introduced to simulate the robustness and vulnerability of the network. It is found that airport ecological network will be collapsed around five time series one after another under the external attack. It also shows that the network will have a global breakdown under a very small external perturbation value when Solanum indicum L. and Callidium villosulum Fairmaire are deliberately attacked. The simulation results show that if the airport authorities give priority to governance these populations of animals and plants with higher in-degree, it may reduce bird strike risk. The analysis results provide a theoretical basis for airport bird strike prevention.
\end{abstract}

\section{Introduction}

Flight safety is seriously threatened by bird strike, this problem can be fundamentally solved when the ecological environment of the airport and its surrounding areas is effectively managed. Various methods are used to reduce the food source, water source and habitat of birds in the airport and its surrounding areas, Bird population should be greatly reduced that birds ecological chain has been destroyed. At present, the research on bird strike prevention mainly focuses on collision prevention, bird strike risk assessment, bird repellent equipment model selection, and ecological environment management etc. [1-3]. These methods are either difficult to implement or too expensive. Cascading failure model of complex networks is used to simulate the ecological network[4], the influence of node fault spreading on the whole network can be studied by analyzing the dynamic characteristics of the network, when the ecological network is destroyed as quickly as possible, the bird population in the airport and its surrounding areas can be effectively reduced. In terms of cascading failures, many models have been proposed by scholars at home and abroad[5-8]. Most of these models are based on simulation to compare the behavior characteristics and diffusion process of cascading failures of various networks under given parameters.

\section{Overview of Meizhou Airport}

Meizhou airport is located in Meijiang district of Meizhou City which is $4 \mathrm{~km}$ away from the urban area. The runway length of the airport is $1800 \mathrm{~m}$, the airport area is $1350 \mathrm{mu}$. Since the completion of construction in
1987, the airport has been continuously reconstructed and expanded, and has become an important domestic airline airport. The area where the airport is located belongs to the subtropical monsoon climate zone, which is the transition zone between the south subtropical and the middle subtropical climate zone. According to the data, the annual average temperature is $21.7^{\circ} \mathrm{C}$, the annual average sunshine hours are $1789.0 \mathrm{~h}-2043.9 \mathrm{~h}$, the average annual rainfall is $1016.3 \mathrm{~mm}-1712.5 \mathrm{~mm}$, and the annual average relative humidity is about $78 \%$.

Meizhou airport is surrounded by Meijiang on three sides which is less than $200 \mathrm{~m}$ away from Meijiang. Jianying Park, Meihuashan Forest Park, Ma'anshan Park, Qiaotou Park, Qinyang Peninsula waterfront wetland park and other ecological parks are located within $5 \mathrm{~km}$ around the airport. Jianying park is only more than 600 meters, which has a great impact on the airport ecology. Meitang village, Sanlong village and Gongqian village, three natural villages, relocation areas and large orchards, farmland and vegetable fields are distributed outside the boundary on both sides of the airport. In addition to the paved pavement of runway, taxiway and apron, the airfield of the airport is all artificial grass planting area.

\section{Research method}

\subsection{Methods of animal and plant investigation}

The bird survey covers the airfield of the airport and the key areas within $5 \mathrm{~km}$ outside the boundary. The sampling intensity of the survey route is more than $20 \%$ of the total survey area. It includes two $2.5 \mathrm{~km}$ transects along both sides of the runway, and 22 transects in

*Corresponding author: qiaoliang@caac.net 
wasteland, farmland, residential area, water area, forest area and artificial grassland within $5 \mathrm{~km}$ outside the boundary. The transect width is $100 \mathrm{~m}$ in open area and $50 \mathrm{~m}$ in other areas.

On the premise of ensuring the reliability of $95 \%$ and accuracy of $90 \%, 36$ plots were set up in plant investigation. The area of arbor and shrub plot is $15 \times 20 \mathrm{~m}^{2}$, and 5 quadrats with area of $2 \times 2 \mathrm{~m}^{2}$ are set in the plot. All plant species, plant number, plant height, frequency, coverage, average height, distribution status and characteristics in the sample plot will be investigated.

The sites for insect collection are grass planting area within the airfield, wasteland and farmland outside the airport boundary, artificial lawn and landscape forest, and aquatic plants along the river. Artificial capture and net capture were used in the daytime, and black light lamp combined with molasses was used to lure and collect at night. The device is evenly arranged in the square grid with a side length of $10 \mathrm{~m}$ on the grassland and in the artificial trees, and which is set every $10 \mathrm{~m}$ along the Meijiang river.

For small mammals and reptiles, traps and drugs were set at the entrance of the cave and on both sides of the airport boundary to collect specimens or take photos from a long distance. Meijiang river is mainly investigated, including the lake in Jianying park for amphibians and fish.

\subsection{Cascading failure analysis method of airport ecological network}

\subsubsection{Cascading failure model in coupled map lattices}

Cascading failure is a very important dynamic behavior of complex networks which has a great impact on the system[9]. Due to the strong or weak coupling between nodes, the chain reaction will make the whole network crash when a node fails. The robustness and vulnerability of the network can be understood by analyzing the dynamic behavior. Ma Xiujuan, Ma Fuxiang, etc. proposed a cascading failure model in coupled map lattices[10]:

$$
\begin{aligned}
& x_{i}(t+1)=\mid\left(1-\varepsilon_{1}-\varepsilon_{2}\right) f\left(x_{i}(t)\right)+ \\
& \varepsilon_{1} \sum_{j=1, j \neq i}^{N_{1}} A_{j i} \frac{f\left(x_{i}(t)\right)}{\operatorname{deg}^{+}(i)}+\varepsilon_{2} \sum_{i=1, i \neq j}^{N_{2}} A_{i j} \frac{f\left(x_{i}(t)\right)}{\operatorname{deg}^{-}(i)} \mid
\end{aligned}
$$

In the formula (1), $x_{i}(t)$ represents the state of $i$ at time $\mathrm{t}, \varepsilon_{1}$ and $\varepsilon_{2}$ represent the coupling strength of the inbound and outbound edges of the node, $f(x)$ is a nonlinear function which represents the dynamic behavior of the node, $N_{1}$ and $N_{2}$ represent the sum of in-degree and out-degree of all nodes, $\operatorname{deg}^{+}(i)$ and $\operatorname{deg}^{-}(i)$ represent the in-degree and out-degree of node $i, A$ represents the adjacency matrix of node connection information.

It can be seen from this formula that if the state $x_{i}(t)$ of node $i$ is always $0<x_{i}(t)<1,(t \leq m)$ in $m$ time series, it indicates that the network is in a normal state. If at any time $m, x_{i}(m) \geq 1$, it means that the node is faulty. At this time and subsequent moments, there will be $x_{i}(t) \equiv 0,(t>$ $m)$.

Assuming that an external disturbance $(R \geq 1)$ is applied to node $i$ at time $m$, the node status is shown below:

$$
\begin{aligned}
& x_{i}(t+1)=\mid\left(1-\varepsilon_{1}-\varepsilon_{2}\right) f\left(x_{i}(t)\right)+ \\
& \varepsilon_{1} \sum_{j=1, j \neq i}^{N_{1}} A_{j i} \frac{f\left(x_{i}(t)\right)}{\operatorname{deg}^{+}(i)}+\varepsilon_{2} \sum_{i=1, i \neq j}^{N_{2}} A_{i j} \frac{f\left(x_{i}(t)\right)}{\operatorname{deg}^{-}(i)} \mid+R
\end{aligned}
$$

At this point, there will be $x_{i}(m)>1$ for node $i$, and the failure will begin. For all $t>m$ moments, there will be $x_{i}(t) \equiv 0$. It can be seen that from time $m$, all neighboring nodes of $i$ will be affected, and the state value of these nodes may be greater than 1 , which will cause the next round of failures and continue to repeat and spread, eventually the entire network will be paralyzed.

\subsubsection{Model improvement}

Node fault transmission is not only related to the severity of the node itself, but also related to the influence of adjacent nodes. Let the attractive modulus between two species be $\lambda_{i j}(t)(i \neq j)$, so $\lambda_{i j}(t) \lambda_{j i}(t)=1$ 及 $\lambda_{i i}=\lambda_{j j}=0$. At a certain time $t$, if the attraction matrix of network nodes is $\left(\lambda_{i j}(t)\right)_{N \times N}$, then formula (1) can be improved as follows:

$$
\begin{aligned}
& \frac{x_{i}(t+1)=\mid\left(1-\varepsilon_{1}-\varepsilon_{2}\right) f\left(x_{i}(t)\right)+}{\varepsilon_{1} \sum_{j=1, j \neq i}^{N_{1}} A_{j i} \lambda_{j i}(t) \frac{f\left(x_{i}(t)\right)}{\operatorname{deg}^{+}(i)}} \\
& \frac{\sum_{j=1, j \neq i}^{N_{1}} \lambda_{j i}(t)}{\sum_{i=1, i \neq j}^{N_{2}} A_{i j} \lambda_{i j}(t) \frac{f\left(x_{i}(t)\right)}{\operatorname{deg}^{-}(i)}} \mid \\
& \sum_{i=1, i \neq j}^{N_{2}} \lambda_{i j}(t)
\end{aligned}
$$

The attractive modulus $\lambda_{i j}(t)$ and $\lambda_{j i}(t)$ in formula (3) can quantify the influence between nodes $j$ on $i$ and $i$ on $j$, so that the node states affected by actions of adjacent can be better reflected. Similarly, when node $i$ is subjected to an external disturbance $R \geq 1$ at time $m$, its state is as follows:

$$
\begin{aligned}
& \frac{x_{i}(t+1)=\mid\left(1-\varepsilon_{1}-\varepsilon_{2}\right) f\left(x_{i}(t)\right)+}{\varepsilon_{1} \sum_{j=1, j \neq i}^{N_{1}} A_{j i} \lambda_{j i}(t) \frac{f\left(x_{i}(t)\right)}{\operatorname{deg}^{+}(i)}} \\
& +\frac{\sum_{j=1, j \neq i}^{N_{1}} \lambda_{j i}(t)}{\sum_{i=1, i \neq j}^{N_{2}} A_{i j} \lambda_{i j}(t) \frac{f\left(x_{i}(t)\right)}{\operatorname{deg}^{-}(i)} \mid} \mid+R \\
& \sum_{i=1, i \neq j}^{N_{2}} \lambda_{i j}(t)
\end{aligned}
$$

\subsubsection{Node failure scale and attack strategy}

Set $I(t)$ as the total number of nodes where the network fails before time $t+1$ and $I$ as the overall scale of network failure when the fault transmission is over, the formula $\mathrm{I} \equiv \lim _{t \rightarrow \infty} I(t) \quad$ can be obtained, the fault scale changes with the development of time series which shows the process 
of fault diffusion.

When external disturbance is applied, random attack and intentional attack can be adopted. A node is randomly or artificially selected to attack. The state values of the node at time $m$ and adjacent nodes at time $m+1$ are calculated by formula (4) and (3).

\section{Research results}

\subsection{Species statistics}

A total of 112 bird species were recorded in Meizhou airport and its surrounding areas, of which Passeriformes was the most abundant, there are 58 species in 18 families, accounting for $51.8 \%$ of all bird species investigated. The number of Ardeidae, Cuculidae and Cuculidae was the second. There are 180 species of wild plants belonging to 106 genera (46 families), and 89 species of cultivated plants. There are 96 species of insects belonging to 78 genera (44 families), among which 36 species are dominant species. There are 63 species of fish, of which Cyprinidae and Belontiidae account for $34.9 \%$ and $46.0 \%$ of all fish species respectively. Among the small animals, there are 19 species of Mammalia in 7 families ( 3 orders), 18 species of Reptilia in 9 families ( 3 orders), and 20 species of Amphibian in 5 families (1 orde).

\subsection{Distribution of animals and plants in high risk area of airport}

Cynodon dactylon (L.) Pers. and Zoysia japonica Steud. are the main plants in grass planting area of airfield, which are mixed with the plant communities of Peristrophejaponica (Thunb.) Bremek., Malachium aquaticum(L.)Fries. (Stellaria aquatica(L.) Scop.), Ixeris denticulata, Pharbitis purpurea (L.) Voisgt, Plantago depressa Willd., these plants will attract Lepidoptera, Earthworm, etc., and attract some birds belonging to Passeriformes, such as Hirundo rustica, Cecropis daurica, Pycnonotus sinensis, Lanius schach and other birds. At the same time, Falco tinnunculus, Tyto longimembris and other raptors will also be attracted because these plants are also important food sources for Glires. In case of continuous rain, Motacilla alba, Sturnus nigricollis, Charadrius alexandrinus and other birds will be found around the ponding area in airfield.

There are many hydrophilic and aquatic plants such as Dicranopteris dichotoma (Thunb.) Berhn., Salvinia natans(L.) All, Ceratopteris thalictroides (L.) Brongn., Parathelypteris glanduligera (Kze.) Ching, Hygrophila salicifolia (Vahl) Nees., Utricularia aurea Lour. near the open drainage channel in airfield, which are food for many aquatic insects. These aquatic insects can also attract Ranidae, such as Ooeidozyga lima, Paa spinosa to live and forage, and to attract Colubridae, such as Elaphe taeniura, Bungarus fasciatus, etc. These aforementioned plants are also food for Pomacea canaliculata and other shellfish. Therefore, some wading birds, such as Little Egret, Nycticorax nycticorax, Amaurornis phoenicurus, which feed on insects and frogs, and some birds of prey, such as Spilornis cheela, Strix aluco, which feed on snakes and frogs, it's often found near the airport drainage channel.

In Meijiang and Jianying Park Lake, wading birds that eat fish, shrimp or frogs, raptors that eat snakes and frogs, even Anas platyrhynchos, Anas formosa and other swimming birds can be seen occasionally, and they live in the artificially cultivated arbor forests near the river, lake or park. More than 20 kinds of artificial trees are planted in Jianying Park, including Bombax ceiba L., Ficus concinna Miq., arvifolia M. Cheng, Pittosporum tobira, etc, there are various common plants on the ground in the forest, such as Alternanthera dentata 'Rubiginosa', Ixeris denticulata, Rumex japonicus Houtt., Coronopus didymous (Linn.) J. E. Smith, etc. These plants can not only attract a variety of omnivorous and carnivorous birds to forage, but also are the habitat of Eudynamys scolopaceus, Pycnonotus jocosus, Pycnonotus sinensis, Sturnus nigricollis, Acridotheres cristatellus (Linnaeus.), Turdus merula and Corvidae, which are common in this area.

Meitang village, Sanlong village and Gongqian village are located outside the boundary on both sides of the airport runway. Oryza sativa L., Zea mays Linn., vegetables, Leguminosae sp., Citrus maxima (Burm) Merr., Dimocarpus longan Lour. and other cultivated crops are planted in these villages all year round. These crops will attract many herbivorous birds, such as Passer montanus and Lonchura punctulata (Ploceidae), Spilopelia chinensis and Streptopelia orientalis (Columbidae), Emberiza aureola (Passeridae). Part of the farmland close to the airport boundary has been expropriated as reserve land, where weeds and shrubs are overgrown. Common shrubs and subshrubs include Cynanchum auriculatum Royle ex Wight., Cassia obtusifolia Linn., Mimosa pudica Linn., Lycium chinense Mill., Solanum indicum Linn., etc, these shrubs are habitat for many birds as Upupa epops, Orthotomus sutorius and Leiothrix lutea (Old World babbler), Passeridae, Copsychus saularis, Phasianidae and so on.

\subsection{Airport ecological network}

\subsubsection{Construction of ecological network}

Birds, small mammals, amphibians or reptiles, insects and plants in Meizhou airport and its surrounding areas are an ecological chain. Plants are both food and habitat, insects are the food of most birds or small animals, and small animals are the food of some raptors. According to the ecological chain relationship between these animals and plants, 21 species of dominant and common birds, 3 species of small mammals, 2 species of amphibians, 4 species of small reptiles, 6 species of fish, 18 species of insects, 17 species of wild plants and 9 species of cultivated plants were selected to construct the ecological chain network of Meizhou airport. These animals and plants have a direct directional relationship with food or habitat, which form the directed edge of the network. The adjacency matrix $A=\left(a_{i, j}\right)_{N \times N}$ is constructed in MATLAB, and then Pajek software is used to generate a directed 
network topology with 81 nodes.

\subsubsection{Network distribution and structure}

Complex networks have scale-free characteristic, which shows that the distribution function of degree presents power-exponent characteristic. It can be seen from the figure 1that the probability of nodes with small in-degree value is relatively high and the probability becomes smaller and smaller with the value increase of node in-degree. Therefore, the degree of Meizhou airport ecological network node has the power-law characteristics.

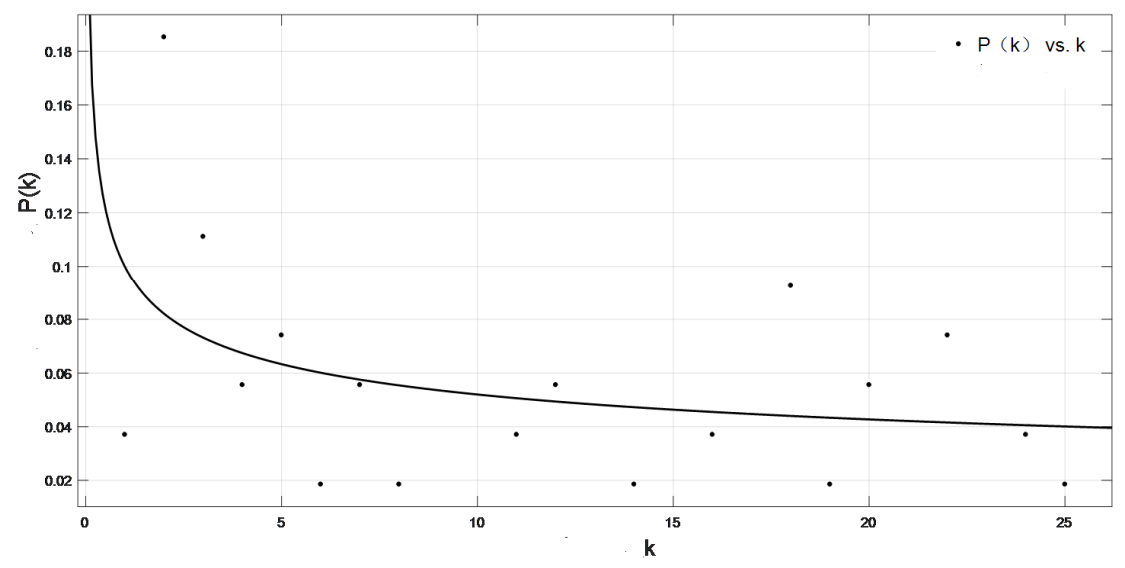

Fig. 1. In-degree distribution probability of nodes in Meizhou airport ecological.
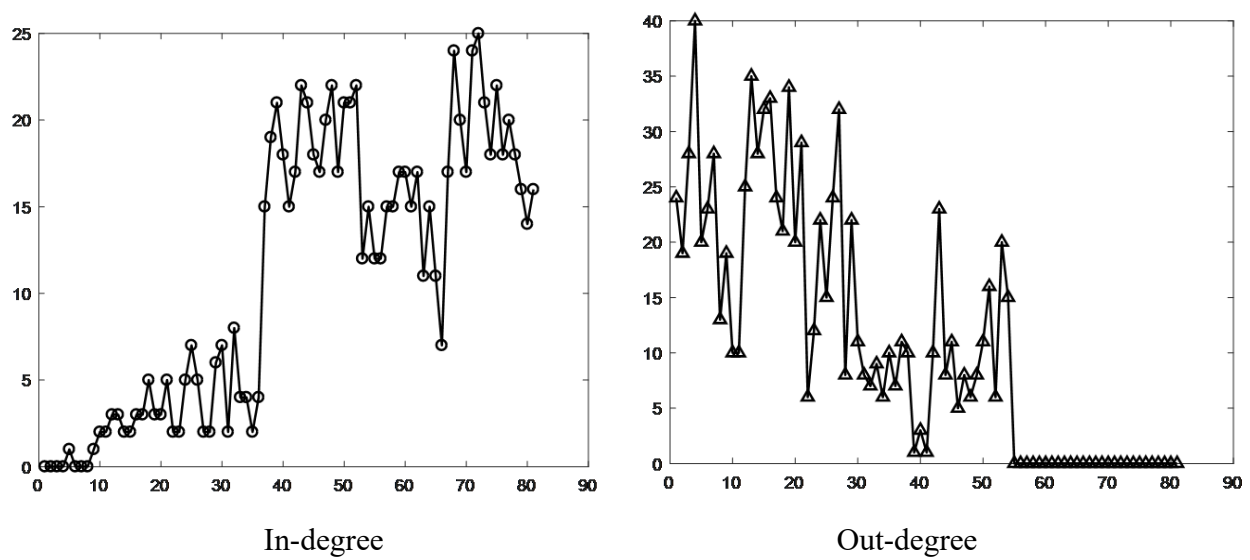

Fig. 2. Scatter diagram of nodes in-degree and out-degree of Meizhou airport ecological network.

The figure 2 shows the values of node in-degree and out-degree in the ecological network, the influence of different species in the ecological network was reflected from different angles. For example, these nine birds as Nycticorax nycticorax, Falco tinnunculus, Amaurornis phoenicurus, Strix aluco, Pycnonotus sinensis, Lanius schach, Acridotheres cristatellus (Linnaeus.), Copsychus saularis, Emberiza aureola are characterized by low in-degree values and high out-degree values, which means that these species have few natural enemies in this ecological environment. However, the high in-degree value of plant population indicates that they are food or habitat for all other animals. And the sum of out-degree and in-degree values of some animal and plant populations is very high, such as Orthotomus sutorius, Podagricomela nigricollis Chen, flies, Elaphe taeniura, they are not only the food of many other animals, but also feed on many animals and plants or live on many plants.

\subsection{Simulation results of cascading faults}

\subsubsection{Simulation parameters}

Firstly, a node is randomly selected and given a random state value less than 1 . Then, external disturbance is applied to the network to simulate the influence on the stability of the network caused by the reduction of the artificially selected population and the randomly selected population, and the fault diffusion is observed in the network.

The principle of representativeness should be adopted in the selection of species for deliberate attack. First of all, Amaurornis phoenicurus with the highest out-degree value was selected. This bird has complex diet and wide habitat environment, which has a great impact on other species. At the same time, in order to consider the danger of hunting birds and various small animals, we chose Falco tinnunculus. Secondly, due to the large number of species with similar in-degree value, we considered to 
select the wild plants Solanum indicum Linn. and insect Callidium villosulum Fairmaire with the largest in-degree value to verify the impact of food shortage or habitat destruction on other animal populations in the network and the cascading failures caused by them. Thirdly, we choose Podagricomela nigricollis Chen with the largest sum of the in-degree and out-degree values between the upper and lower species which is used as deliberate target to analyze the impact on the nodes at both ends of the network when their number decreases.

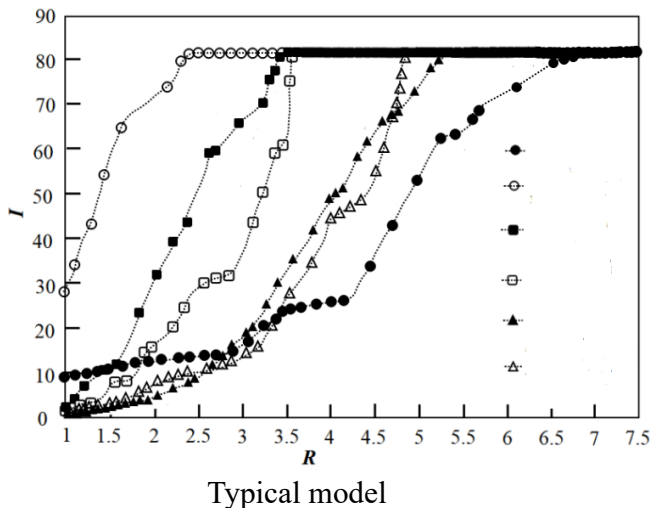

\subsubsection{Simulation results}

Let the input side coupling strength $\varepsilon_{1}=0.2$ and the outlet coupling strength $\varepsilon_{2}=0.6$, set $f(x)$ be a chaotic logistic mapping function as $4 x(1-x)$, the simulation was carried out by programming in MATLAB, and the average value of 50 experimental data was taken. Under the two attack strategies, the variation curve of fault scale marked as $I$ with disturbance value $(R \geq 1)$ and the diffusion process at any time $t$ of the selected species in 20 time series are shown in figure 3 and figure 4 in the typical model and the improved model. The table 1 shows the critical values of disturbance when the network reaches "avalanche" with different attack strategies under the two models.

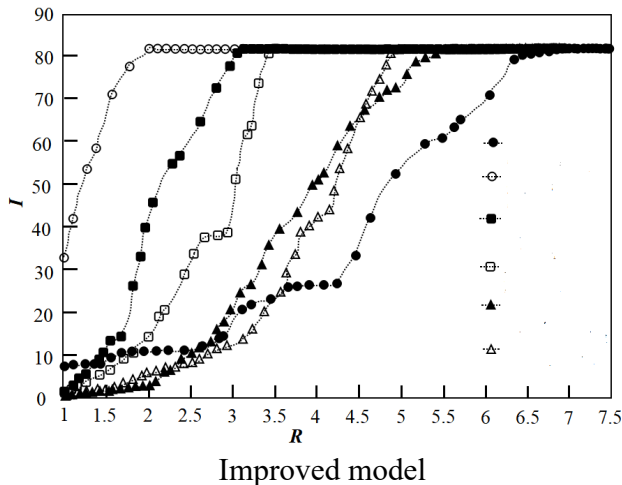

Fig. 3. Relationship between cascading failure scale and disturbance value in directed networks under different attack strategies.

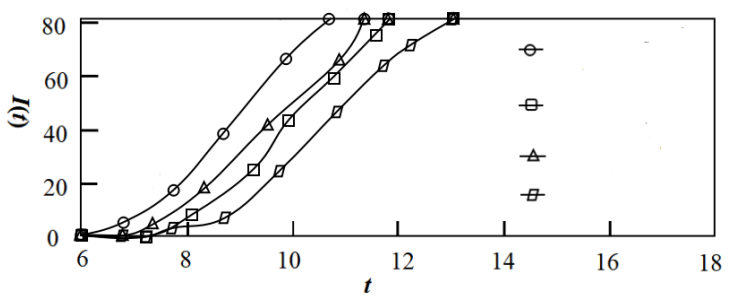

Typical model

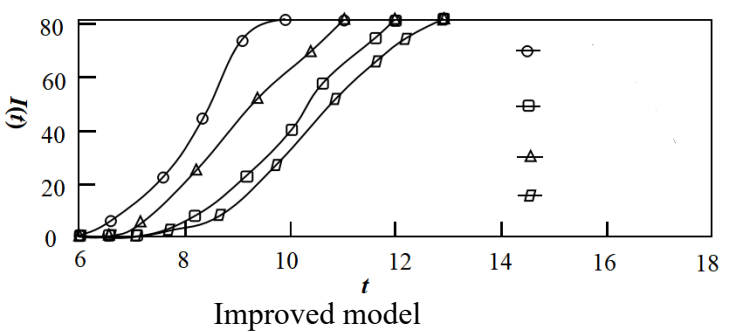

Fig. 4. Time spreading process of cascading faults in directed networks.

Table 1. Critical disturbance value under different attack strategies in two models.

\begin{tabular}{|c|c|c|c|c|}
\hline \multirow{8}{*}{$\begin{array}{l}\text { Attack } \\
\text { strategy }\end{array}$} & \multirow{4}{*}{$\begin{array}{l}\text { Critical value of } \\
\text { disturbance in } \\
\text { typical model }\end{array}$} & $\begin{array}{c}\text { Deliberate attack } \\
\text { (Plant with the highest } \\
\text { in-degree value) }\end{array}$ & $\begin{array}{c}\text { Deliberate attack } \\
\text { (Animal with the highest } \\
\text { in-degree value) }\end{array}$ & $\begin{array}{c}\text { Deliberate attack } \\
\text { (Specie with the highest } \\
\text { degree value) }\end{array}$ \\
\hline & & 2.34 & 3.36 & 3.45 \\
\hline & & $\begin{array}{c}\text { Deliberate attack } \\
\text { (Animal with the highest } \\
\text { out-degree value) }\end{array}$ & $\begin{array}{c}\text { Deliberate attack } \\
\text { (Carnivorous animal with } \\
\text { the highest out-degree } \\
\text { value) }\end{array}$ & Random attack \\
\hline & & 5.25 & 4.73 & 6.77 \\
\hline & \multirow{4}{*}{$\begin{array}{l}\text { Disturbance } \\
\text { critical value in } \\
\text { improved model }\end{array}$} & $\begin{array}{c}\text { Deliberate attack } \\
\text { (Plant with the highest } \\
\text { in-degree value) }\end{array}$ & $\begin{array}{c}\text { Deliberate attack } \\
\text { (Animal with the highest } \\
\text { in-degree value) }\end{array}$ & $\begin{array}{c}\text { Deliberate attack } \\
\text { (Specie with the highest } \\
\text { degree value) }\end{array}$ \\
\hline & & 1.95 & 3.09 & 3.48 \\
\hline & & $\begin{array}{c}\text { Deliberate attack } \\
\text { (Animal with the highest } \\
\text { out-degree value) }\end{array}$ & $\begin{array}{c}\text { Deliberate attack } \\
\text { (Carnivorous animal with } \\
\text { the highest out-degree } \\
\text { value) }\end{array}$ & Random attack \\
\hline & & 5.50 & 4.86 & 6.73 \\
\hline
\end{tabular}


As shown in the figure 3, the impact of attacks on any deliberately selected species on the ecological network is much stronger than that of random attacks, and the influence of random attacks is relatively weak. When deliberately attacking the species with the largest in-degree and degree value, with the increase of disturbance value, the network paralysis speed is much faster than that of deliberately attacking the species with the largest out-degree value. As can be seen from Figure 4, no matter what attack strategy is adopted, the directed network will be paralyzed in about five time series. The disturbance critical values in Table 1 show that when the maximum plant population Solanum indicum Linn. is deliberately attacked, the whole network will collapse when the minimum disturbance value in the improved model is 1.95 .

\section{Analysis and discussion}

By exerting influence on the important population and spreading to the whole network through fault transmission, the number of other populations in the ecological chain can be changed, and the ecological balance of the whole network will be affected. The results show that the ecological network will collapse rapidly when the plant population with the largest in-degree value is attacked intentionally at the minimum disturbance critical value. This is because most omnivorous birds and phytophagous birds directly feed on the plant or use it as a habitat. If the plant decreases, it means that these birds are short of food and lack of habitat. At the same time, all kinds of small animals and insects that feed on the plant will also decrease, which will indirectly lead to the decrease of the species that feed on these small animals and insects. Eventually, the whole ecological network will collapse soon. When the animal with the largest in-degree value is attacked, it will directly reduce the number of carnivorous and omnivorous animals, and slow down the network collapse speed, which requires a slightly larger external disturbance. When the animal with the largest sum of the in-degree and out-degree values is attacked intentionally, less plants will be consumed due to the decrease of the animals, and the external disturbance value will be larger when the network collapses globally. Finally, it can be seen that when the animal with the largest out-degree is attacked intentionally, other birds, small animals and plant populations have no direct or indirect natural enemies, which makes the collapse speed of the ecological network very slow, and the disturbance value required in the intentional attack mode is the largest.

The simulation analysis and comparison of different models for network attack process also shows that when different species are attacked, the larger in-degree value will make the node fault transmission speed in the improved model faster than that in the typical model with the increase of disturbance value, and the line type with time sequence change is more steep; with the increase of the disturbance value, the fault propagation speed of the improved model is faster than that of the typical model. When out-degree value becomes large, the change is just the opposite. The reason for this is that the influence between adjacent nodes is considered in the improved model. With the increase of node degree value, the overall influence also gradually increases. From the perspective of the original network balance being broken, in-degree value is positively correlated with the influence and out-degree value is negatively correlated, which makes the fault curve change most obviously in the improved model when the species with the largest in-degree value is attacked. However, the species with the largest degree value of nodes have relatively small changes due to the relatively large in-degree and out-degree, whose influence of each other is offset. In a word, the attractiveness coefficient is introduced to improve the cascading failure model in coupled map lattices, the simulation results of Meizhou airport ecological chain network show that the model considering the influence between nodes can more accurately and objectively reflect the changes of the network state under external interference, it provides a more objective basis for the airport to reduce the incidence of bird strike through ecological environment management.

For the airport authorities, in order to affect the ecological network of Meizhou airport and its surrounding areas as quickly as possible, and reduce the number of bird populations and the frequency of coming to the airport by means of ecological environment management, the government should focus on the control of plants and insects with large in-degree value. By means of artificial, chemical and physical methods, the berry shrubs in Meizhou airport airfield and within the range of $6 \mathrm{~m}$ outside the boundary are completely removed, and regular insecticidal and insecticidal measures are carried out, so as to effectively control the food source or habitat of birds with high risk level, in order to effectively reduce the frequency and incidence of bird strike and improve flight safety under the limited human and material resources of the airport.

\section{Conclusions}

A improved cascading failure model in coupled map lattices is introduced to simulate the robustness and vulnerability of the network. The application in Meizhou airport shows that the model considering the influence of nodes can more accurately and objectively reflect the change of node state when the network is disturbed by external interference. Artificial, chemical, physical and other methods which are used to remove and manage the large population in the ecological network, the main bird habitat, direct or indirect food sources in the airport can be eliminated. As a result, the incidence of bird damage in the airport is greatly reduced and the flight safety is improved.

\section{References}

1. Tuo T L, Li H H. Study on the ecology of summering birds and birds striking avoidance in Guilin Liangjiang Airport[J]. Journal of Xinyang 
Normal University (Natural Science Edition), 2002, 20(2): 95-98.

2. Zhu J, Li Y L. Research for the Instantaneous velocity measurement in aircraft bird-impact test[J]. Measurement and Control Technology, 2003, 22(12): 5-7.

3. Wang Z G, Zhou F, Li X L, et al. Bird risk assessment for bird strike prevention and control at airports[J]. Ecologic Science, 2007, 26(1): 69-74.

4. Ding L, Zhang C Y. Survey on cascading failures on Complex Networks[J]. Computer Science, 2012, 39(8): 8-13.

5. Motter A E, Lai Y C. Cascade-based attacks on complex networks[J]. Phys. Rev. E, 2002 , 66(6): 65-102.
6. Wang X F, Xu J. Cascading failures in coupled map lattices[J]. Phys. Rev. E, 2002 , 70: 56-113.

7. Watts D J. A simple model of global cascades on random networks[J]. Proc. Natl. Acad. Sci. U.S.A, 2002, 99: 5766-5771.

8. Guo Q, Li L X, Chen Y H, et al. Modeling dynamics of disaster spreading in community networks [J]. Nonlinear Dyn, 2011, 64: 157-165.

9. [13] Albert R, Barabasi A-L. Statistical mechanics of complex networks[J]. Review of Modern Physics, 2002 , 74(1): 47-97.

10. Ma X J, Ma F X, Zhao H X. Cascading failure in coupled map lattices with directed network[J]. Journal of Computer Applications, 2011, 31(7): 1952-1955+1979. 